Res Publica. Revista de Historia de las Ideas Políticas ISSN-e: 1989-6115

http://dx.doi.org/10.5209/rpub.66177

\title{
El demonio de Goethe: el Eros de la obra
}

\author{
Christa Bürger*
}

Recibido: 11 de abril de 2019 / Aceptado: 4 de octubre de 2019

Resumen. El presente artículo forma parte de un proyecto sobre "arte luciferino" que la autora ha desarrollado junto con Peter Bürger, centrado en la realidad del arte. Christa Bürger analiza aquí la concepción del artista y la creación que Goethe plantea en Poesía y verdad. El artista aparece aquí como alguien que se apodera de la existencia de figuras de la vida real y se las arrebata, y esto resulta particularmente notorio en las figuras femeninas de Goethe, en las que se lleva a cabo una desrealización de la mujer. En último término se trata de la autoproducción del artista y del lado oscuro de la creación, y particularmente de la dimensión luciferina de la misma.

Palabras clave: Goethe; Poesía y verdad; creación; ficción; arte luciferino.

\section{[en] Goethe's Demon: the Eros of the Work}

\begin{abstract}
The present paper is part of a wider project the author has developed together with Peter Bürger. This project focuses on the reality of art. Christa Bürger analyzes in this paper the conception of the artist and the creation developed by Goethe in Dichtung und Wahrheit. The artist appears here as someone who takes posesion of the existence of real characters, which seems to be particularly the case of Goethe's female characters, where he seems to operate a desrealization of women. What is at stake here is the self-production of the artist and the dark side of creation, or more precisely its luciferin dimension.
\end{abstract}

Keywords: Goethe; Dichtung und Wahrheit; Creation; Fiction; Luciferin art.

Cómo citar: Bürger, C. (2019). El demonio de Goethe: el Eros de la obra, en Res Publica 22.3, 613622.

\section{Nota preliminar}

Quisiera presentar una parte de un proyecto que Peter Bürger y yo hemos desarrollado juntos. La obra resultante, que Peter Bürger no pudo acompañar hasta el final, lleva el título provisional "Arte luciferino". Dicho brevemente, el libro se centra en la realidad del arte.

Aun antes del auge de la estética de la recepción en la década de los 70, habíamos sospechado que el concepto de ficción - tan utilizado en la definición de las obras

Johan Wolfgang Goethe Universität Frankfurt am Main 
literarias- tenía un momento ideológico. A nuestro modo de ver, el concepto de "ficción" resta importancia y desempodera al arte. Porque el arte nunca es inofensivo, tal y como insiste Lou Andreas-Salomé, la amiga de Nietzsche y Rilke, que sabía lo que decía. Con ello se refiere al hecho que la obra merecedora de tal nombre necesita la producción del sujeto artístico. El ejemplo de Rimbaud es bien conocido. "Je travaille à me rendre voyant", reconoce y admite que, al igual que el sorcière de Michelet, recurre al principio satánico de la inversión: “Imaginez un homme s'implantant et se cultivant des verrues sur le visage". Rimbaud califica como trabajo esta autopreparación monstruosa. Cuando Goethe, en conversación con Eckermann, reflexiona sobre si debe anteponerle a la última parte de Poesía y Verdad el "descomunal dicho" nemo contra deum nisi deus ipse, pero por fin desiste deliberadamente de ello, muestra que conoce el misterio de ese trabajo, pero lo quiere guardar para sí. Pero a nosotros el lema spinoziano -que aún hoy no es verificable-nos revela mucho sobre la concepción que Goethe tiene del artista y de su creación de las obras, en absoluto inofensiva, con la cual se apodera de la existencia de figuras tomadas de la vida, arrebatadas a ella. El concepto del narrador omnipotente, que se ha convertido en un topos trivial, retiene un saber que la teoría de la literatura reprime. Dante, el devoto poeta de la Baja Edad Media, hace uso de esta omnipotencia del narrador de forma grandiosa. En su Divina Commedia se erige como juez sobre vivos y muertos, usurpando así la sentencia divina del Juicio Final.

En el topos se esconde un problema que no es sólo teórico. La autocreación del artista se corresponde con la pretensión de realidad de la obra. Ello se puede apreciar de forma ejemplar en la carta con la que Goethe responde a la solicitud de Charlotte y Johann Christian Kestner de que aplace la entrega del Werther. "Está hecho, está entregado, perdonadme si podéis". La referencia blasfema al "se ha consumado" del crucificado remite al acto de creación artística: la transformación de la vida vivida en la realidad de la obra, la "resurrección" de la existencia casual como forma eterna. Desde el momento de la publicación del Werther de Goethe, Lotte y Kestner se convierten en modelos novelísticos que les sobrevivirían.

Así pues, mi propuesta se centra en la autoproducción del artista, pero también en la dimensión más oscura de su creación. El último registro de Peter Bürger en nuestro diario común reza: "La diferencia de género es la diferencia más profunda. Si se desmiente, cae la forma y con ella la cultura". Con ello se señala ya la temática que nos ocupará. A su manera, Goethe ha ayudado a forjar la imagen tradicional de lo femenino que aún hoy mantiene su influencia. Yo he criticado la desrealización de la mujer en sus obras una y otra vez. Y cada vez se imponía una reflexión: que ahí se escondía el miedo del hombre Goethe ante la realidad del sexo opuesto, ante la "impresión aterradora" de una mujer desnuda a la vista del autor de Cartas desde Suiza, escondido tras la máscara del Werther, que como anónimo pintor viajante ansiaba ver desnuda a una de las chicas de un burdel, y nada más que eso.

Después de muchos años trabajando sobre la vida, el amor y la escritura de mujeres, desde Madame de Sévigné hasta Simone de Beauvoir, he llegado al punto de preguntarme de qué fuentes se alimenta un conocimiento del amor tan inconmensurable como el de Goethe. Para saber tanto como él, sería necesario ser Tiresias, del

J. W. Goethe, Carta a Johann Christian y Charlotte Kestner, octubre de 1774, en Goethes Werke. Weimarer Ausgabe, IV. Abteilung, vol. 2, Weimar, H. Böhlau, 1887, p. 200. [Todas las referencias son de los editores]. 
que Ovidio cuenta que ha conocido el amor "desde los dos lados"2, como hombre y como mujer. La comprensión que Goethe posee del orden de género, tal y como fue difundido por la Nouvelle Héloise de Rousseau, se podría deber a este tipo de ambigüedades. Es así: Goethe ha pensado y vivido dentro de este orden. Lo ha expuesto en sus figuras y en sus múltiples formas de relación, pero, escondido a su manera detrás de sus imágenes, ha hecho reconocible lo inescrutable de este orden: en la misteriosa cajita que aparece de forma inesperada en diversos lugares en Poesía y Verdad y en los Años de Peregrinaje. O en la confesión de culpa que hace en el monodrama Proserpina, surgida seis meses después de la temprana muerte de su hermana. Y en el grito de Helena al final del tercer acto de Fausto II, con el que vuelve al reino de las tinieblas de Perséfone. La desaparición de Helena es causa y motivo de la obra, la renuncia a un instante que es, sin embargo, la condición de su perduración en la OBRA: "Ya no es la diosa que perdiste, pero es divina"3.

Un último comentario sobre la forma de exposición. Podrá apreciarse que pretendo realizar una "crítica redentora" en el sentido de Walter Benjamin. Pero quizás también -y eso me parece especialmente importante- que no deben esperar una construcción teórica, sino un recorrido a través de los textos, teoría como narración.

$$
* * *
$$

"Todo aquello que saben de mí solo son fragmentos de una gran confesión", reconoce el viejo Goethe en el séptimo libro de Poesía y verdad ${ }^{4}$. Es una frase que se ha citado a menudo. Pero, $¿$ se la ha tomado tan en serio como hizo el propio autor, que en la siguiente página habla de una "penitencia tormentosa", cumplida con el "tratamiento dramático" de un episodio de juventud? Si se toma en serio esta referencia, se pone en duda la concepción predominante del artista y su obra. La pregunta no es cómo confiesa el artista, sino -y preguntando de forma menos inocente-qué tiene que confesar. El mismo Goethe lo plantea así cuando recuerda aquello que conmovió al joven autor del Werther.

Descansad ahora, como se dice, en el anhelo de la mayor dicha, y el auténtico anhelo solo debe dirigirse a lo inalcanzable. Así, todo coincidió para hacer del joven que ahora acompañamos en sus devaneos el más feliz de los mortales ${ }^{5}$.

En dos ocasiones Goethe se dejó llevar por este anhelo regido por el azar: primero en su amor hacia una "prometida ya adjudicada", Charlotte Buff, y poco después en su veneración por la infelizmente casada Maximiliane Brentano.

El recién llegado, libre de toda atadura, se dejó llevar despreocupadamente en presencia de la joven que, asimismo, no interpretó el complaciente servicio como una solicitud y se alegró de él tanto más confiadamente ${ }^{6}$.

Ovidio, Metamorfosis. Libros I-V, Madrid, Gredos, 2008, p. 338.

J. W. Goethe, Faust. Zweiter Teil, Goethes Sämtlicher Werke in vierzig Bänden, vol. 12, Stuttgart y Tubinga, Cotta'scher Verlag, 1840, p. 222.

4 J. W. Goethe, Dichtung und Wahrheit, en Sämtliche Werke: Briefe, Tagebücher und Gespräche, vol. 14, Frankfurt am Main, Surhkamp, 1986, p. 310 (en adelante DuW seguido de la página).

5 DuW, p. 594.

6 DuW, p. 591. 
Durante un verano, Goethe vive en una "agitación apasionada", que desde el principio tiene un momento irreal. Como no espera un amor correspondido y no trata de ganárselo, puede gozar del propio amor y reconducir las energías eróticas liberadas gracias a su renuncia hacia el proceso creador. Ello le permite escribir en pocas semanas -“casi como un sonámbulo"- la novela del Werther. Porque ya había encontrado su objeto. "No podía dejar de insuflar [...] toda mi pasión a esa producción, una pasión que no permitía diferenciar entre lo poético y lo real"7. Al igual que Dios, que creó a Adán insuflándole vida a su criatura. Había conseguido poner su energía amorosa al servicio de la creación poética. Esta feliz armonía de renuncia y satisfacción - a la que se debe la novela- revela la pulsión central de la creatividad de Goethe: el Eros de la palabra creadora.

Siempre que su tema es la relación entre poesía y verdad -como en la historia del surgimiento de su obra de juventud, que hizo famoso al autor-, los fragmentos que Goethe nos transmite sobre su gran confesión hablan de una "terrible criatura", que llega a llamar diabólica. Este "ser que todo lo penetra", que "parecía reinar de forma arbitraria sobre todos los elementos necesarios de nuestra existencia", se manifiesta en el procedimiento del artista, que utiliza sus propias vivencias como material y dispone libremente de la realidad. Las personas con las que se encuentra se transforman bajo la influencia de esa "terrible criatura". Pasan a formar literalmente parte de su obra: dan lugar a figuras de tal realidad que hacen que los modelos que originariamente las habían inspirado se desvanezcan.

Conducido por el anhelo hacia lo realmente imposible de la obra de arte, que en cada instante puede confundir con alguna forma de cariño, el joven Johann Wolfgang observa un espectáculo encantador: una grácil joven vestida con un sencillo vestido blanco con lazos de un pálido color rosa en sus brazos y en su pecho, que corta a sus hermanos pequeños rebanadas de pan negro, a cada cual según su edad. Él ha retenido la imagen, junto con otros "elementos que desde hace algunos años rondan su mente". Pero todavía le faltaba una "oportunidad, una fábula en la que pudiera encarnarse". De modo que cuando recibe la noticia del inesperado suicidio de Jerusalem -que, como asesor del tribunal cameral de Wetzlar, está entre sus conocidos más próximos-, de repente comprende que el juego con los apegos puede ser mortal, y así da con el plan para el Werther. Como si quisiera mantener a distancia la conmoción causada por esta muerte, se refugia en una peculiar comparación, inspirada en las ciencias naturales:

El conjunto se aglutina por todas las partes hasta convertirse en una masa sólida, como agua en un recipiente a punto de congelarse y que, a la menor sacudida, se convierte de repente en un hielo sólido ${ }^{10}$.

Esta metáfora parece tener un motivo particular. Vuelve a aparecer en una formulación parecida, aparentemente más inofensiva, de una carta tardía de Goethe en relación a la figura de Helena en Faust II. Goethe escribe al científico Nees von Esenbeck, que ha "solidificado (ha transpuesto en forma sólida)" a la "milenaria

\footnotetext{
DuW, pp. 638 y ss.

DuW, p. 840.

DuW, p. 636.

DuW, p. 636.
} 
Helena", que ahora podrá perdurar en ese estado. Si se toma en su literalidad, la comparación describe el surgimiento de la novela como una trasposición de la vida al frío punto de congelación de la forma.

Y efectivamente Goethe acomete medidas precisas para no dejar pasar ese "punto de congelación". En su interior, deja de lado todo lo que le pudiese distraer de la repetición de todos esos momentos vitales de los que "todavía no ha hecho uso poético" convertir en Lotte a la hermosa hija de funcionarios Charlotte Buff, que reparte el pan vespertino a sus hermanos en la antesala del "Deutsches Haus".

Como escribe el autor en Poesía y Verdad, con la redacción del Werther ha acometido una "confesión general" y, gracias a ello, se siente "autorizado para una nueva vida". Pero, ¿realmente leemos el Werther como una confesión? ¿O más bien como una novela de amor? Si tomamos "confesión general" en su pleno significado, remite a que el penitente confiesa todo sin subterfugios. Pero, ¿puede realmente confesar alguien que ha hecho del incógnito su modus vivendi? ¿O está obligado -como a mi parecer sucede en el Werther-a desplazar la confesión de su persona a la obra, ocultando y desvelando al mismo tiempo? Aquello que la novela de amor oculta, lo desvela la confesión autobiográfica, "a medias poética, a medias histórica". Probablemente la novela y la historia de su surgimiento arrojan una confesión. Pero esta confesión testifica la "total no-inocencia del arte", para decirlo con una expresión de Lou Andreas-Salomé a propósito de Rilke. Nos revela la imagen de un artista para el que el auténtico amor hacia la prometida de un amigo y la auténtica muerte de otro amigo son los motivos a los que se debe la obra, que tergiversa lo real y lo irreal hasta hacerlos indiscernibles. Johann Wolfang se enamora de verdad de la joven hija de funcionario o, mejor dicho, se deja prendar por ella, pero -por así decir- de incógnito. Goethe, el joven autor, se enamora -como quedará escrito para la posteridad- de la novela de amor en la que se enredó para poder escribirla. Y entonces se marcha como renunciante, según el propio Goethe. Pero la amada y su amigo, el prometido, a los que ha convertido en personajes de su novela, quedan atrás. Se ha producido un robo, una desrealización que la posterior reconciliación apenas podrá enmendar. Porque el Werther de Goethe existe, expulsando con ello a la Charlotte real y al Kestner real al reino de las tinieblas de Perséfone.

La siniestra realidad de la obra también se hace patente en su extraordinario impacto, prácticamente sin par en la historia. Los coetáneos hablaban de una "fiebre de Werther", vivida como una especie de enfermedad mortal, pese a que -de hecho- sólo se atestiguasen pocos suicidios inspirados por la novela. El propio Goethe le escribe a Charlotte von Stein su plan de erigir un monumento a la joven Christiane von Laßberg, que supuestamente había puesto fin a su vida por un amor frustrado saltando al río Ilm. La habían encontrado cerca de la residencia de verano de Goethe y la custodiaron en casa de Charlotte von Stein. Se dice que llevaba consigo el Werther. En su carta, Goethe advierte a Charlotte que no baje al río. "Porque esta pena irradia una peligrosa seducción, parecida a la del agua misma" En la primera versión del poema A la luna, el propio Goethe se ve a sí mismo "cautivado por el río como un fantasma". Aún 50 años más tarde, bajo la impresión de

DuW, p. 639

12 J. W. Goethe, Carta a Charlotte von Stein del 19 de enero de 1778, en Johann Wolfgang Goethe Briefe. Historisch-Kritische Ausgabe, Band 3 I, Berlín, De Gruyter, p. 191. 
su última gran renuncia, la separación de Ulrike von Levetzow, Goethe se refiere a Werther -"aquella sombra largamente llorada"- como a un amigo cuyo destino ha cantado él, el poeta: "Yo fui elegido para continuar, tú para fallecer, y así fuiste en cabeza sin tanto perder..."13.

A Goethe le gustan los continuos, y así la confesión de la época del Werther entra en una constelación furtiva con el Musterstück al principio de Poesía y Verdad: El nuevo Paris. Cuento de un muchacho [ein Knabenmärchen]. Goethe había vinculado los orígenes del Werther con una "preparación histórica", la época del Sturm und Drang, pero sobre todo se había concentrado en los "motivos éticos" de su obra". Trata como un cuento de hadas aquello que antecede a la creación de la obra: la autocreación del artista.

El subtítulo del cuento de un muchacho produce irritación, porque la búsqueda del significado de este fragmento - cuyo nombre de género lo conecta con el trato en parte poético de la biografía de Goethe-, conduce en direcciones muy diversas. No resulta fácil dirimir a qué se refiere: ¿es el cuento de un muchacho, sobre un muchacho, para un muchacho? Lo más probable es que sea todo al mismo tiempo. Pues a sus pequeños amigos de infancia -así inicia Goethe su Musterstück- les gustaba especialmente cuando contaba sus cuentos "en persona". También este cuento nos habla del poeta y de su obra, pero aquí también lo hace sobre sus efectos. El joven Johann Wolfang mistifica a sus oyentes "con figuras irreales y meras fantasías", con ficciones por tanto. "Los poetas mienten", como dice una frase que habría tomado de su antiguo profesor de griego. Goethe se calma con la idea de que sus jóvenes oyentes se engañan a sí mismos al creer que sus aventuras se basan en vivencias reales, pues conocían sus hábitos y podían saber que era imposible que él hubiese estado en esos escenarios en aquellos momentos, que manejaba a su antojo el tiempo y el espacio, de forma absolutamente arbitraria. De modo que sus éxitos podrían haber acabado haciendo de él un verdadero fanfarrón, de no haber estado allí su pulsión de "transformar sus ocurrencias en representaciones artísticas". El viejo Goethe reconoce en esa pulsión - que se había manifestado prematuramente- "cierta arrogancia con la cual el poeta expresa altivamente lo más improbable y exige que cualquiera reconozca como real aquello que a él, el creador, le haya parecido de un modo u otro verdadero" $" 15$. Esta reflexión -que Goethe convierte en una pequeña frase artística sobre la obra de arte- mantiene todo en el aire, todas las palabras se revelan ambiguas. Aquí, la palabra "arrogancia" no resuena en tono peyorativo. Más bien, la frase invalida la aserción de los pensadores clásicos sobre la mentira de la poesía y vincula la obra poética con los conceptos de verdad y realidad, pese a que su interrelación resulte confusa e indefinida. ¿Quiere el narrador que sus oyentes consideren real su poesía? ¿O que la reconozcan como real? ¿Se explica la impresión de la realidad porque a él le parece verdadera de un modo u otro? Está claro que no se trata de que la poesía coincida con la realidad, de la verdad fáctica de lo narrado, sino de la realidad de la narración que atestiguan las vivencias del narrador. En la arrogancia del poeta se hace patente una autocomprensión demoníaca. Su arrogancia es una usurpación. El narrador, que dispone de sus experiencias como material, entra en competencia con el Creador. Así lo ve el propio Goethe, como delata un paralipómeno de Poesía

\footnotetext{
J. W. Goethe, “An Werther”, Berliner Ausgabe. Poetischer Werke, vol. 9, Berlín, Aufbau, 1960, p. 250.

DuW, pp. 588 y ss.

DuW, p. 58.
} 
$y$ Verdad que el autor no recogió en el texto publicado. En ese fragmento, Goethe reconoce que siempre se ha sentido un elegido, que siempre ha estado convencido -en palabras de Freud- de la omnipotencia de su pensamiento. "Me podrían haber puesto una corona y yo habría pensado que eso iba de suyo"16.

Con el título mitológico del cuento, el autor de Poesía y Verdad pone al lector sobre una pista falsa. Al entrar en el jardín hechizado, al joven narrador del cuento le corroe la angustia de no dar la talla ante las aventuras que le esperan. Los pájaros le saludan a la llamada de “¡París! ¡París!”, pero en seguida cambian a “¡Narciso! ¡Narciso!”, revelando así -a él y a nosotros- que sus anhelos no se dirigen a Helena, la más hermosa de las mujeres, sino a la narración misma. Lo que le incita a adentrarse cada vez más en ese jardín -cuyas puertas se habían cerrado con un silencio estremecedor a su espalda- es el deseo de una materia que le había convertido en narrador: el Eros de la obra. Él es Narciso, aquel que rehúye la muerte en su deseo de verse reflejado en... sus creaciones. Las exclamaciones de los pájaros certifican el genio artístico que le espera al final de su camino, en unos jardines artísticamente concebidos y surcados por los recuerdos del Viaje a Italia.

Un sueño nocturno en vísperas del domingo de Pentecostés prepara al joven para las aventuras de esta excursión. De modo que la narración pone el suceso, en parte mitológico y en parte alegórico, en una relación implícitamente blasfema con el milagro de Pentecostés, la venida del Espíritu Santo. Porque también el sueño alude a una vocación: un joven, al que reconoce enseguida como Hermes, le entrega tres manzanas - una roja, una amarilla y una verde-, con el encargo de repartirlas entre los jóvenes más bellos, que así podrían hacerse más apetecibles. El emisario divino desaparece, y en manos del joven las manzanas se convierten en tres "preciosas mujeres del modesto tamaño de una muñeca". Pero en cuanto intenta aferrarlas se disuelven en el aire. No puede atrapar ni a la "más encantadora de estas jóvenes", que de repente baila sobre la punta de sus dedos. Entonces se despierta. Sólo a través de la narración comprende que a él, el nuevo París, no le corresponde la más bella de las mujeres, sino el don de la narración. Y eso significa poder disponer de los destinos amorosos y vitales de las tres parejas.

En el cuento, la excursión del muchacho por el jardín encantado y encantador se convierte progresivamente en una iniciación. Un portero que le resulta siniestro le deja pasar a condición de que se deshaga de su traje, su sombrero y su espada y se vista con un vestido oriental, lo que -por otra parte-concuerda con la propensión del joven a disfrazarse, que siente enseguida a gusto en su "atuendo".

Es sabido que Goethe amaba el incógnito, un estado que implicaba al mismo tiempo enajenación y una percepción intensificada desde la posición de la tercera persona a la que nadie reconoce: la petulancia luciferina del artista creador que ve sin ver visto, sin ser reconocido como aquel que es. En la casa parroquial de Sesenheim es presentado como candidato a teólogo sin recursos. Pero en tanto que Goethe divisa a Friederike Brion, la hija más joven de la casa, y la ve como la vemos desde entonces y la veremos siempre: una graciosa jovencita de campo vestida con un traje nacional que ya apenas se utiliza, "en el linde entre la campesina y la urbanita". "En el instante en que apareció en la puerta una estrella encantadora resplandeció en el cielo campestre..." Friederike, la imagen que ha hecho de ella, cobra realidad ahora para nosotros, los lectores de Poesía y Verdad.

16 DuW, p. 932. 
El muchacho, vestido con su traje oriental -es decir, de incógnito-, se halla en la sala de columnas de la casa de verano, que claramente imita la descripción de la Rotonda del Viaje a Italia, se encuentra de pronto con las tres mujeres de su sueño de Pentacostés tocando el arpa, la cítara y el laúd, que aparecen con el "efecto sensual-moral" del rojo, amarillo y verde de su Teoría de los colores. Enseguida las identifica como Hera, Athenea y Afrodita, y abandonándose a la vista y al oído goza de la encarnación de los personajes de sus sueños. Con cierto alivio descubre que existe un placer más allá del deseo, y que esta antesala del amor es la condición para la creación artística. Entiende que "no hay motivo" para aferrarse a las bellezas, por muy seductoras que sean. Porque él ya conoce su misión. Pero se deja distraer de nuevo: por el tintineante sonido de la mandolina y el baile de la pequeña Alerte, la "joven preferida" del sueño. Pero la competición en la que se enreda pronto se convierte en una desagradable disputa. El joven Johann Wolfang se enfurece en cuanto advierte que - a pesar de su incógnito- ya no es dueño de la situación, y que su misión puede verse comprometida. Sobre todo cuando el puente dorado sobre el que ocurre la disputa de repente se tambalea y le arroja al muro por donde el viejo portero le había dejado entrar. Al mismo tiempo, un diluvio le azota por todas partes. Pronto está completamente empapado, su traje de seda hecho jirones, y él, desnudo y helado, se encuentra de pie ante una puerta cerrada. En su vergüenza, en sus inútiles esfuerzos por cubrir su desnudez, se siente una "figura extremadamente miserable" cuando el viejo portero se alza de nuevo ante él y le amenaza con un castigo. Esta situación recuerda al muchacho algunas impresiones que había pasado por alto al entrar en el jardín. “iNarciso!“, le habían llamado los pájaros, advirtiéndole de que no se perdiera en su propio reflejo. Pero él se había deleitado en su disfraz. El portero le había explicado el significado de los cordeles de seda verde, que había visto en el espejo que colgaba de un pequeño gancho al fondo, mientras admiraba su imagen como príncipe Paris en versión oriental. Había pasado por alto esta amenaza de muerte, que conocía de los cuentos de las 1001 noches, como también los elementos mitológicos en el jardín: la villa de las tres diosas, rodeada de columnas, estaba circunscrita por un círculo de álamos y cipreses. Unos árboles que daban sombra y que no solo pertenecen al paisaje bucólico de Arcadia, sino también al reino de Perséfone, señora del Hades. En cualquier caso conocía bien el dicho "Et in Arcadia ego". De modo que, aunque la figura del muchacho tenga un momento caricaturesco, tanto en su desnudez indefensa como en su traje de domingo con el sombrero y el sable, está al mismo tiempo rodeado por un aura de misterio, el origen de la creación artística.

La amenaza del portero hace que el joven narrador vuelva literalmente en sí: el viejo y las mujeres son criaturas de su fantasía poética y no tienen más realidad que la que él las concede. Él -GOETHE-, está llamado a ser un "favorito de los dioses", encargado de crear como ellos. Esta explicación, que le sorprende a él mismo, le transforma de nuevo en un muchacho que se pavonea en su flamante y solemne vestimenta.

Johann Wolfgang Goethe ha experimentado el poder de la narración, el efecto de sus propias palabras. Pero también quiere saber qué significan para él mismo. De modo que el final de la aventura no es todavía el final de su relato. Cuando el viejo le deja salir le recomienda que recuerde el lugar para que pueda volver a encontrar la puerta escondida. $\mathrm{Y}$ el muchacho graba todo en su memoria: las ramas del viejísimo nogal que sobresalen del muro, llegando hasta una tabla de piedra en la repisa de un 
nicho sobre un pequeño pozo. La tabla contiene una inscripción que no logra descifrar. Algo más tarde vuelve a encontrarlo todo, pero su forma ha cambiado. Ahora la puerta ha desaparecido, pero la inscripción de la tabla resulta legible: "Probablemente, cuando todo coincida, la puerta volverá a ser visible. Entonces haré lo imposible para retomar mi aventura" 17 .

El viejo Goethe, que describe el lugar donde comienza el relato de forma tan clara, no revela lo que un día de muchacho leyera en aquella tabla sobre la repisa situada bajo el nogal. Me imagino que es la frase con la que introduce su historia de amor por Lili Schönemann en su biografía: "Todo nos llama para que renunciemos". Resulta revelador que esta última parte de Poesía y Verdad se deba a la insistencia de Eckermann, que estaba preparando una edición póstuma de las obras de Goethe y había observado que el progreso de la obra se había atascado. Para despertar un "nuevo impulso" que permitiera retomar el trabajo interrumpido, envió algunas notas a Goethe. La disposición del conjunto tiene mucho de novela, "una apasionada relación amorosa", "alegre al comienzo", "trágica al final con la tácita renuncia recíproca"18. Eckermann reconoce en el esquema diseñado por Goethe una novela de amor trágica. Pero lo trágico en esta novela no consiste tanto en su desenlace -la separación de los amantes-, sino en que Goethe, que solo había podido eludir del encanto de la graciosa joven mediante una reiterada huida, llega a una conclusión sobre sí mismo en su "condición de novio": es incapaz de amar. Pues "Bienvenida y Despedida" bien podría ser el título de la relación del poeta con la joven hija del banquero.

Fue una extraña decisión del todopoderoso que reina sobre nosotros que en el transcurso de mi misteriosa biografía llegase a tener la experiencia de sentir lo que siente un prometido ${ }^{19}$.

Goethe finaliza el último libro de Poesía y Verdad con una autocita del Egmont: la imagen de los "caballos de sol del tiempo", que "como espoleados por espíritus invisibles" "pasan con el carro ligero de nuestro destino", mientras que quien marcha entusiasta siente ya cómo lo vivido queda atrás y apenas resulta ya accesible al recuerdo. De modo que no puede ser casual que en este final Goethe vuelva de nuevo a Spinoza, cuya filosofía de la renuncia había introducido la novela de Lili. Su "confianza en Spinoza" -admite- "se debía al efecto pacificador que producía en él" y le incitó a "no forjar sino conceptos indestructibles", conceptos que no pudieran ser revocados por la contemplación de lo efímero. Goethe sabía que los seguidores de Spinoza estaban expuestos a la sospecha de herejía, y eso le reafirmó en sus propias especulaciones teológicas sobre la esencia de lo diabólico. Y estas son de tal calado que casi le podrían haber atribuido "cuernos y zarpas" ${ }^{20}$. Porque giran de un modo inquietante en torno a la divisa que Goethe y Eckermann querían anteponer a este último libro: Nemo contra deum nisi deus ipse ${ }^{21}$. Inquietante, porque Goethe quería captar algo que "ningún concepto y menos aún una palabra puede captar", porque "solo se manifiesta en contradicciones" y porque de repente este algo se transfor-

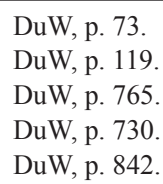


ma en una figura que - de modo apenas velado- deja entrever sus propios rasgos: Goethe, el que ama el incógnito. La criatura contradictoria que ha descubierto en la naturaleza desde la "confianza en Spinoza" no es humana ni divina, no es diabólica ni angélica, pues unas veces fue benéfica y otras se alegró del mal ajeno. "Parecía actuar de forma arbitraria con los elementos necesarios de nuestra existencia. Estrechó el tiempo y ensanchó el espacio". "Se encuentra en una relación portentosa con el ser humano y constituye un poder que, cuando no se contrapone al orden moral de las cosas, lo desbarata". "A esta criatura, que parece entrometerse entre todos los demás para separarlos y unirlos, la llamaré diabólica, siguiendo el ejemplo de los antiguos $^{22}$. El modelo se encuentra en el Banquete de Platón, en el que la hetaira filosófica Diótima explica a Sócrates la esencia del eros y se lo describe como un gran demonio, "áspero, de aspecto desagradable, descalzo, sin techo". Un caminante sin descanso que persigue lo bello, pero no para poseerlo, sino para "la producción y el nacimiento en lo bello". Este Eros desea lo bello en aras de las bellas obras que crea a partir de lo bello. Un artista que crea el ser de la nada ${ }^{23}$. Con la enigmática frase que finalmente descarta como divisa, Goethe regresa de la especulación sobre el Eros y lo diabólico a su propia historia de amor, revistiendo su "pequeña vida" con una "apariencia diabólica" ${ }^{24}$ y se ve por vez primera ante la decisión de si quiere seguir al Eros de la obra, a su demonio, o prefiere ser el novio. Ante esta encrucijada opta por la huida, recordando ese grito al principio de la novela de Lili. Y el azar le socorre personificado en el duque de Sajonia-Weimar, que le invita a su corte. El poeta condensa el tiempo que ha pasado con Lili en un único instante de despedida, para nosotros incomparable e inolvidable: "Envuelto en un gran abrigo deambulé por la ciudad y no dejé de acercarme a la ventana de Lili... Pronto la escuché cantar junto al piano, y era la canción: “ $¡ A y$, cuán irresistiblemente me atraes!, que había compuesto para ella apenas un año antes"25. Y expande infinita-mente este tiempo de amor, porque mantiene vivo en la figura de Egmont -en la obra- lo que su espíritu ya había dejado atrás. "Mediante este acto, oh Sócrates - dijo ella- todo lo mortal participa de lo inmortal" 26 .

Traducción de Conrad Lluis Martell revisada por Jordi Maiso

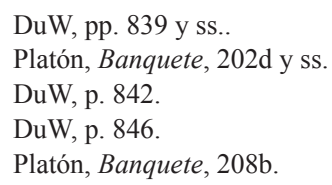

